\title{
DIAGNÓSTICO DA FLORICULTURA NO RIO GRANDE DO SUL
}

\author{
DIAGNOSIS OF FLORICULTURE IN RIO GRANDE DO SUL, BRAZIL
}

\author{
Atelene Normann Kämpf ${ }^{1}$ Rafael Schüür Daudt ${ }^{2}$
}

\begin{abstract}
O objetivo deste trabalho foi avaliar o segmento da produção de flores e plantas ornamentais no Rio Grande do Sul, Brasil, por meio de um levantamento a campo. O estudo faz parte de um projeto global, apoiado pelo Instituto Brasileiro de Floricultura (IBRAFLOR) e pelo Ministério da Agricultura e do Abastecimento (MAARA), através do Departamento Nacional de Cooperativismo (DENACOOP). Com base nos formulários preenchidos nas propriedades, foi elaborado um cadastro dos floricultores, com seus endereços e produções. A floricultura gaúcha conta com 257 produtores, que cultivam o total de 304 ha em 65 municípios; $30 \%$ dessa área é ocupada com flores de corte, $33 \%$ com mudas para jardim, $29 \%$ com outros produtos da floricultura e $8 \%$ com plantas envasadas. $O$ sistema de cultivo predominante é a céu aberto (89\%), com baixos investimentos tecnológicos.
\end{abstract}

Palavras-chave: floricultura, estatística, flores e plantas ornamentais.

\section{SUMMARY}

A survey was conducted to quantify flower and ornamental plant production in the State of Rio Grande do Sul State, Brazil. The Brazilian Floriculture Institute (IBRAFLOR) and the Agriculture Ministry (MAARA - DENACOOP) granted this research. Based on an inventory formulary a catalog including the nurseries, addresses and main crops was elaborated. There are 257 growers in this State with an area of 304 ha distributed among 65 counties; $30 \%$ of this area are cultivated with cut flowers, $33 \%$ with annuals and perennials for garden, $29 \%$ with other floriculture products and $8 \%$ with potted plants. The main system of cultivation is not protected with low technological investments.

Key words: floriculture; statistics; flowers and ornamental plants.
Há cerca de dez anos vem sendo noticiado na mídia que o Rio Grande do Sul compra de outros Estados, especialmente de São Paulo, significante parcela das flores e plantas ornamentais que aqui se consomem. Com base nos Boletins Mensais da Ceasa-RS, a única estatística disponível, os dados dessa dependência variam entre 70 e $90 \%$.

Desde 1994, entretanto, com a criação da AFLORI - Associação Rio-Grandense de Floricultura, o setor tem mostrado sinais promissores de desenvolvimento no Estado, organizando-se em busca da integração dos diversos elos da cadeia, tendo como meta a profissionalização em todos os níveis.

Dentro deste espírito, em 1996 foi realizado um trabalho de pesquisa a campo, com o objetivo de diagnosticar a situação da floricultura estadual. Com base em levantamento prévio, monitores realizaram visitas e entrevistas individuais nos municípios onde foi possível constatar a existência de produtores de plantas ornamentais. Esse trabalho realizado pela Faculdade de Agronomia da UFRGS, foi patrocinando por um convênio entre o Instituto Brasileiro de Floricultura (IBRAFLOR) e o Ministério da Agricultura e Abastecimento (MAARA). Contou ainda com o apoio da Secretaria da Agricultura e Abastecimento do Rio Grande do Sul e da Associação Rio-grandense de Floricultura (AFLORI). O projeto global integrou os levantamentos nos Estados de São Paulo, Santa Catarina, Minas Gerais, Espírito Santo e Rio Grande do Sul. A relação dos floricultores resultou na publicação de

\footnotetext{
${ }^{1}$ Biólogo, Doutor, Professor no Departamento de Horticultura e Silvicultura, Faculdade de Agronomia da Universidade Federal do Rio Grande do Sul (UFRGS), CP 776, 90001-970, Porto Alegre/RS. Bolsista CNPq. Autor para correspondência.

${ }^{2}$ Acadêmico de Agronomia, UFRGS. Bolsista de Iniciação Científica do CNPq. 
cadastros regionais, com os nomes, endereços e especificação dos produtos cultivados nas diversas propriedades, em cada Estado (IBRAFLOR, 1996; AMIFLOR, 1996; UFRGS, 1996; APROESC, 1997).

Os dados obtidos em 1996 demostraram que a floricultura no Rio Grande do Sul reúne 257 produtores, ocupando a área total de 304 hectares em cultivo (UFRGS, 1996), distribuídos entre 62 municípios (figura 1). A maior concentração das floriculturas (42\%) encontra-se em cinco municípios: Pareci Novo, São Sebastião do Caí, Porto Alegre, Capela de Santana e Farroupilha. Entre os estabelecimentos cadastrados predominam os da iniciativa privada $(89 \%)$, seguindo-se os mantidos por prefeituras municipais e/ou órgãos estaduais (9\%) e os referentes a estabelecimentos de ensino (2\%). A média geral é de 4,1 produtores por município amostrado.

Com alta rentabiliade por área produzida, a floricultura tem contribuído para viabilizar as pequenas propriedades rurais. $\mathrm{O}$ emprego da mão de obra está em torno de quatro pessoas por hectare, muito superior à ocupação das atividades rurais similares. As empresas de floricultura no Rio Grande do Sul têm forte cunho familiar: mais de um terço da mão de obra (38\%) corresponde à família. Apesar da reduzida extensão da área em cultivo, $46 \%$ dos produtores ainda empregam funcionários assalariados, que correspondem a $62 \%$ da mão-de-obra, quer como mensalistas $(57 \%)$ ou como diaristas (5\%). Portanto, além de auxiliar na fixação da população

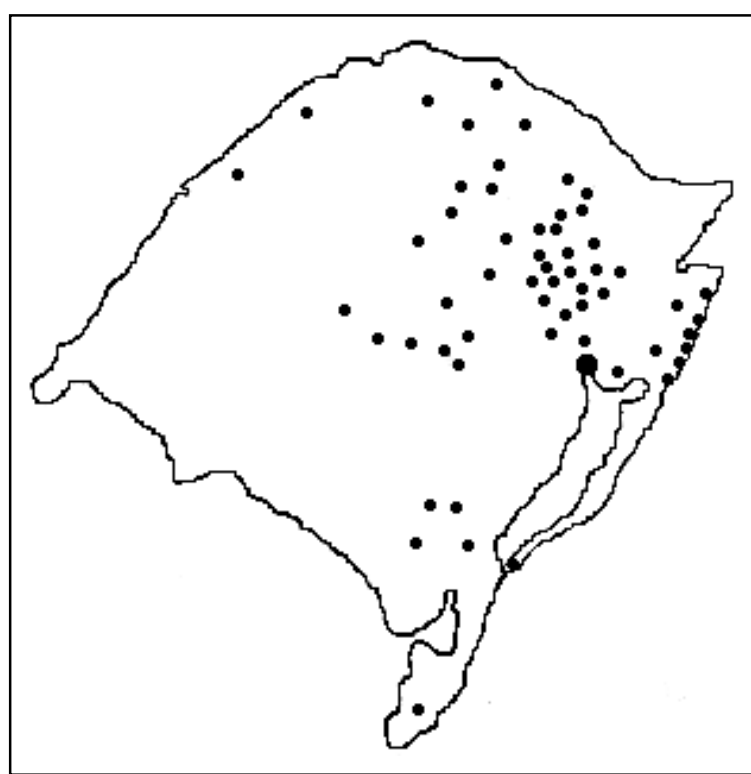

Figura 1 - Localização dos municípios amostrados. rural, o setor também se destaca como gerador de empregos em atividades agrícolas e o floricultor passa a assumir o perfil de empresário rural.

A maioria dos floricultores gaúchos (89\%) produz em área própria e $11 \%$ utilizam áreas arrendadas. A extensão total das propriedades envolvidas nesta atividade varia desde pequenas áreas, menores do que 1,0ha, até áreas com mais de 1000ha. Na média, cada propriedade cultiva 1,2ha com plantas ornamentais.

O levantamento demonstra que $45 \%$ dos produtores cultivam flores e folhagens de corte, $45 \%$ dedicam-se às mudas de flores e plantas para jardins, $31 \%$ produzem plantas envasadas, enquanto $8 \%$ são responsáveis por outros produtos da floricultura, como leivas de grama para gramados. Alguns floricultores restringem sua produção a um só grupo de plantas, porém muitos diversificam seus produtos em mais de uma categoria.

Considerando a área total em cultivo, $33 \%$ estão ocupadas com mudas de plantas para jardim, em especial árvores e arbustos; 30\% cultivam flores-de-corte, como crisântemos e rosas; $29 \%$ cultivam outras espécies e em $8 \%$ são produzidas plantas em vaso, como samambaias, folhagens, crisântemo de vaso e violeta africana (tabela 1).

As características climáticas das áreas com floriculturas no Estado (tabela 2) sugerem que as baixas temperaturas podem ser fator limitante ao crescimento das plantas ornamentais. Apesar disso, apenas $1 \%$ da área cultivada está sob telado para sombreamento e $10 \%$ contam com estufas; a maior parte da produção é realizada a céu aberto. Em São Paulo, a proporção entre a área de produção a céu aberto e a área em cultivo protegido é de 2:1 (ARRUDA et al. 1996), indicando maior nível tecnológico no setor da floricultura. A melhoria do pro-

Tabela 1 - Caracterização da produção de flores e plantas ornamentais no Rio Grande do Sul: extensão em hectares conforme os grupos de plantas e o sistema de produção.

\begin{tabular}{|c|c|c|c|c|c|}
\hline \multirow{2}{*}{$\begin{array}{c}\text { Grupo de } \\
\text { Plantas }\end{array}$} & \multicolumn{3}{|c|}{ Sistemas } & \multicolumn{2}{|l|}{ produção } \\
\hline & Céu aberto & Telado & Estufa & Total (ha) & $\%$ \\
\hline Flores de corte & 72,84 & 0,21 & 12,02 & 91,24 & 30,0 \\
\hline Plantas de vaso & 5,40 & 0,78 & 8,01 & 23,72 & 7,8 \\
\hline Mudas de jardim & 99,82 & 2,54 & 10,79 & 100,97 & 33,2 \\
\hline Outras & 91,72 & 0,00 & 0,00 & 88,20 & 29,0 \\
\hline Total & 269,77 & 3,53 & 30,83 & 304,13 & 100,0 \\
\hline$\%$ & 88,7 & 1,2 & 10,1 & 100,0 & \\
\hline
\end{tabular}


Tabela 2 - Características climáticas nas regiões produtoras de flores e plantas ornamentais do Rio Grande do Sul.

\begin{tabular}{lcc}
\hline \multicolumn{1}{c}{ Características climáticas } & Unidades & Valores \\
& & \\
\hline & & \\
Médias anuais: & & \\
Temperatura mínima & ${ }^{\circ} \mathrm{C}$ & 10 a 16 \\
Temperatura máxima & ${ }^{\circ} \mathrm{C}$ & 22 a 26 \\
Amplitude térmica & ${ }^{\circ} \mathrm{C}$ & 8 a 14 \\
Temp. mínima absoluta & ${ }^{\circ} \mathrm{C}$ & -8 a 6 \\
Temp. máxima absoluta & ${ }^{\circ} \mathrm{C}$ & 34 a 38 \\
Precipitação total anual & $\mathrm{mm}$ & 1250 a 2000 \\
Horas médias de sol brilhando & $\mathrm{h}$ & 1600 a 2400 \\
Umidade relativa do ar média & $\%$ & 75 a 85 \\
Dias de chuva por ano & dias & 90 a 120 \\
& & \\
\hline
\end{tabular}

(Fonte: BRASIL, 1969).

duto estadual, tanto na qualidade como na disponibilidade, exige maiores investimentos em infra-estrutura e tecnologia.

O consumo de flores e plantas ornamentais no Rio Grande do Sul é reconhecidamente acima da média nacional: com base em informações estatísticas obtidas na CEASA/RS, em 1992 (não publicado), calculava-se o consumo de US\$23.00 per capita/ano em flores. Em palestra sobre o tema, o especialista em mercado, Francisco Bonger, situou o consumo médio brasileiro em US\$6.00 ao ano, enquanto a média na Argentina estaria em torno de US\$25.00 ao ano.

Os dados levantados indicam que o mercado interno gaúcho absorve basicamente toda a produção do Estado. Entre os produtos exportados, destacam-se mudas de floríferas para a Itália, orquídeas para o Japão, e rosas para a Alemanha. O mercado também importa flores. Nas datas de maior consumo, como Dia das Mães, Dia dos Namorados e Finados, constata-se que o aumento na demanda justifica a crescente importação de rosas e gipsofilas da Colômbia, Equador e Chile.
Dois sistemas predominam na comercialização dos produtos da floricultura gaúcha: o primeiro corresponde à venda em lojas especializadas, mediante pronta entrega; o segundo é o de venda direta na propriedade, tanto para o varejista, como para o atacadista ou mesmo ao consumidor final. Apenas 6\% dos produtores declararam usar os canais de comercialização da Ceasa-RS.

Conforme o Instituto de Economia Agrícola de São Paulo (ARRUDA et al., 1996), o mercado brasileiro de flores e plantas ornamentais movimenta, anualmente, cerca de um bilhão de reais. $\mathrm{O}$ Estado de São Paulo é responsável por $70 \%$ deste mercado. Especialistas acusam a expectativa de crescimento em $20 \%$ ao ano, extensivo aos três segmentos da cadeia produtiva: produção, distribuição e comercialização. Neste contexto, a participação do Rio Grande do Sul ainda é muito reduzida, limitando-se a $10 \%$ do volume nacional.

\section{REFERÊNCIAS BIBLIOGRÁFICAS}

AMIFLOR. Cadastro da floricultura mineira e capixaba. Associação mineira de floricultura. Belo Horizonte, 1996, 153 p.

APROESC. Cadastro dos produtores de flores e plantas ornamentais de Santa Catarina. Joinville, 1997, 36 p.

ARRUDA, S.T., OLIVETTE, M.P.A., CASTRO, C.E.F. Diagnóstico da floricultura do Estado de São Paulo. Revista Brasileira de Horticultura Ornamental, Campinas, v. 2, n. 2, p. 1-18. 1996.

BRASIL. MINISTÉRIO DA AGRICULTURA. Atlas Climatológico do Brasil. Rio de Janeiro: ECEPLAN, Escritório de Meteorologia, 1969.

BOLETIM MENSAL DA CEASA-RS. Porto Alegre: Central Estadual de Abastecimento, 1977.

IBRAFLOR. Catálogo de produtos produtores de flores e plantas ornamentais dos Estados de Rio de Janeiro e São Paulo. Organizado por C.E.F Castro e C. Nishi. Campinas, SP, 1996, 55 p.

UFRGS. Cadastro de produtores de flores e plantas ornamentais do Rio Grande do Sul. Porto Alegre: Núcleo de Floricultura/UFRGS, 1996, 101 p. 